\title{
Clinical Educators' Perceptions of Students Following a Simulation-Based Learning Program
}

\author{
Sally Hewat \\ University of Newcastle, Australia, sally.hewat@newcastle.edu.au \\ Joanne Walters \\ The University fo Newcastle, Australia, joanne.walters@newcastle.edu.au \\ Emma Caird \\ The University of Queensland, Australia, e.leach@uq.edu.au
}

See next page for additional authors

DOI: https://doi.org/10.30707/TLCSD4.3/JRCE8530

Follow this and additional works at: https://ir.library.illinoisstate.edu/tlcsd

Part of the Other Rehabilitation and Therapy Commons

\author{
Recommended Citation \\ Hewat, Sally; Walters, Joanne; Caird, Emma; Aldridge, Danielle; Penman, Adriana; Cardell, Elizabeth; \\ Davenport, Rachel; Davidson, Bronwyn; Howells, Simone; McCabe, Patricia; Purcell, Alison; Ward, \\ Elizabeth; and Hill, Anne E. (2020) "Clinical Educators' Perceptions of Students Following a Simulation- \\ Based Learning Program," Teaching and Learning in Communication Sciences \& Disorders: Vol. 4: Iss. 3, \\ Article 9. \\ DOI: https://doi.org/10.30707/TLCSD4.3/JRCE8530 \\ Available at: https://ir.library.illinoisstate.edu/tlcsd/vol4/iss3/9
}

This Scholarship of Teaching and Learning Research is brought to you for free and open access by ISU ReD: Research and eData. It has been accepted for inclusion in Teaching and Learning in Communication Sciences \& Disorders by an authorized editor of ISU ReD: Research and eData. For more information, please contact ISUReD@ilstu.edu. 


\title{
Clinical Educators' Perceptions of Students Following a Simulation-Based Learning Program
}

\begin{abstract}
Purpose: Clinical education is a key component of speech-language pathology university curriculum, whereby students have the opportunity to apply theoretical knowledge and practical skills learned in the classroom into a real workplace. However, more recently the availability of high quality, consistent clinical placements and learning experiences across the range of practice areas in the discipline is reducing. Therefore, alternative clinical learning opportunities that enable students to develop skills and competencies are being explored. Recently, replacing clinical time with a simulated learning program has been shown to achieve equivalent levels of clinical competency in speech pathology. However, it is unknown how simulation impacts on student learning in traditional clinical placements. Therefore, this research explored clinical educators' perceptions of students undertaking clinical placements in their workplace immediately following a five-day simulation-based learning program related to the same area of practice.

Method: Thirty-five clinical educators who supervised students in the workplace immediately after they completed the simulation program participated in semi-structured interviews. All interviews were transcribed verbatim and analyzed using qualitative methods described by Graneheim and Lundman (2004).

Result: The analysis identified four key themes related to the impact of students in the workplace, simulation priming students for learning, the importance of the transition from simulation-based learning to the workplace, and the role of simulation in clinical education programs.

Conclusion: The use of simulation to support student learning and develop clinical skills and competencies in adult speech pathology practice is supported by workplace clinical educators. However, results of this study suggest that the simulation program needs to be embedded within the curriculum and clinical education program to enhance transition between learning experiences and maximize benefits of learning experiences in real workplace contexts.
\end{abstract}

\section{Keywords}

clinical education, simulation, workplace learning, speech-language pathology, students

\section{Cover Page Footnote}

Thisresearch forms part of the Embedding Simulation in Clinical Training in Speech-language Pathology project, supported by funding from the Australian Government, Department of Health, under the Simulated Learning Environments Program.

\section{Authors}

Sally Hewat, Joanne Walters, Emma Caird, Danielle Aldridge, Adriana Penman, Elizabeth Cardell, Rachel Davenport, Bronwyn Davidson, Simone Howells, Patricia McCabe, Alison Purcell, Elizabeth Ward, and Anne E. Hill 


\section{Introduction}

Clinical education is an essential part of any professional degree in health. In speech-language pathology (SLP) programs clinical education is explicitly embedded as an integral component of the academic curriculum. The primary goals of clinical education are for students to develop occupational and professional competency-based skills and attributes, to facilitate the student to be a lifelong learner, and to prepare them for complex work environments (McAllister \& Lincoln, 2004). Internationally, SLP programs have mandated requirements for academic and clinical education components. In Australia, SLP programs ensure that all graduates demonstrate entry-level competency, as defined by Competency-based Occupational Standards (Speech Pathology Association of Australia, 2011), whereas in the United States students are required to complete a minimum of 400 clock hours of supervised clinical experience plus demonstrate a number of other standards in order to obtain a certificate of clinical competency (Council for Clinical Certification in Audiology and Speech-Language Pathology of the American Speech-Language-Hearing Association, 2013). Regardless of the process followed, SLP students are assessed in clinical practice contexts to demonstrate competency prior to entering the workforce (McAllister et al., 2011).

The benefits of clinical education undertaken in the workplace are well documented for students and clinical educators (CEs). Students are able to apply their learning of theoretical or conceptual knowledge to occupational practice (Cantatore et al., 2016) through the clinical education process, preparing them as graduates for real world workplaces. As well as gaining both technical and non-technical skills, socializing students into the profession is also acknowledged as an important aspect of workplace learning (Higgs, 2012; Richard, 2008). Clinical education undertaken in a range of settings allows the student to gain an understanding of the breadth of workplaces in which SLPs work and the teams they will work with in managing client care.

CEs, on the other hand, benefit from access to the latest evidence and emerging research through engagement with university students and training programs, recognition for contributing to the development of the profession through teaching and mentoring the new generation of SLPs, enhanced opportunities to recruit graduates to their workplaces through exposure/experience, and the potential to increase productivity (Speech Pathology Australia, 2018). For clinicians in private practice, student-led clinical services have the potential to help clinicians increase the dosage of their interventions to meet evidence-based recommendations (Sokkar et al., 2019).

Despite these benefits, provision of suitable clinical education experiences can present challenges for workplace CEs (McAllister, 2005) whereby supervision of students impacts time management and productivity (Johnson et al., 2017). For many clinicians, clinical education can be seen as an additional responsibility rather than a core duty, with the consequence that many CEs do not have time to develop their craft as educators (Delany \& Malloy, 2018).

For universities, the growth in the number of SLP programs has led to increased student numbers and subsequent difficulty sourcing workplace placements and providing quality clinical education for all students across typical practice areas (McAllister, 2005; Speech Pathology Australia, 2018). As such, there is an increasing need for universities and workplaces to work together to develop flexible or innovative placements and learning opportunities that are more indicative of the changing role and delivery of SLP practice (Briffa \& Porter, 2013; Johnson et al., 2017). 
Simulation is one way that students can develop their clinical skills and competencies in preparation for workplace experiences and the changing work environment. A number of studies across a range of health professions have highlighted benefits of simulated-based learning for students (Blackstock et al., 2013; Hayden et al., 2014; Imms et al., 2018; Watson et al., 2012). Within SLP specifically, there is a growing body of evidence to support the use of simulation within program curricula (Dudding \& Nottingham, 2018; Hill et al., 2012; Howells et al., 2019; Miles et al., 2016; Penman et al., 2020; Ward et al., 2015; Zraick, 2013), and the majority of studies have reported that students enjoy and value their experiences in simulation.

Recently, a national investigation on the use of simulation in SLP education was funded by the Australian government (Speech Pathology Association of Australia, 2018). The primary study in this program of research involved a non-inferiority, randomized controlled trial (RCT). The results demonstrated that SLP students achieved a statistically equivalent level of competency in clinical placements when approximately $20 \%$ of the placement time was replaced with simulation, compared with traditional workplace placements involving no simulation (Hill et al., 2020). For this RCT, 325 SLP students were recruited from six Australian universities in the middle third of their undergraduate or master's program who were required to complete an adult-focused placement at an intermediate level of clinical competence development (McAllister, Lincoln, Ferguson \& McAllister, 2013). The students were randomly allocated into either Group 1 traditional workplace clinic ('traditional' arm) or Group 2 simulation clinic followed by the remainder of their placement at a traditional workplace clinic ('simulation+traditional' arm). Traditional workplace clinics attended by students in both groups were typical of those regularly utilized by each university for adult-focused clinical placements.

The simulation clinic (Group 2) was a five-day simulation-based learning program specifically designed to develop SLP students' clinical knowledge and skills in the management of adults with communication and swallowing disorders. The simulation-based learning program was designed to be undertaken immediately prior to an intermediate level, adult-focused clinical placement, and all students had completed at least one prior "novice to intermediate" level clinical placement. The program was comprised of 13 simulations, involving seven different clinical cases based on real case scenarios from traditional workplace clinics for adult patients. Each simulation within the program was designed to ensure provision of quality teaching and learning in a safe learning environment (Ker \& Bradley, 2014). Students had the opportunity for repeated practice within a simulation, repeated exposure to specific cases, as well as repeated opportunities to practice specific clinical tasks across multiple cases/scenarios (e.g., conducting swallowing assessments during simulation 5, 8, 9, 10 and 11). Students completed the five-day simulation program in groups of six to eight students, however, within each simulation, the students had the opportunity to practice clinical skills individually as well as reflect on their own learning. Feedback was embedded across the simulation program, whereby students gained group and peer feedback during the debriefing sessions, as well as individual feedback directly from the simulation CE, and feedback from simulated patients (actors). On the final day of the simulation-based learning program students participated in a group discussion supported by simulation CE. This discussion encouraged students to reflect on learning during the simulation program and how new knowledge and skills would transfer and impact learning in the traditional clinical placement. Students were encouraged to share their learning goals with the $\mathrm{CE}$ in the traditional clinical placement, however they were required to maintain confidentiality in regard to simulation clinic. A summary of the timetable and 
simulations included in the five-day program is provided in Appendix A and further details regarding the development of the simulation-based learning program for adult practice in SLP are reported by Hewat et al. (2020).

While previous research suggests that SLP students have positive perceptions of simulationbased learning (Penman et al., 2020a), and simulation-based learning builds student competency in adult SLP practice (Hill, et al 2020), there is limited research exploring the perspectives of CEs regarding simulation and its use as a clinical training model. A recent study (Penman et al., 2020b) explored students' and CEs' perceptions of simulation-based learning undertaken immediately prior to a traditional clinical placement. The results highlighted the shared view that simulation offers unique learning benefits that prepare students for clinical placements in the workplace. While this study offered some insights into CEs' perspectives of simulation-based learning, the participant numbers were small and further exploration is warranted.

Therefore, one of the secondary aims of the Australian investigation on the use of simulation in SLP education, and the focus of the current study, was to explore workplace CEs' perceptions about students entering traditional workplaces for clinical placements following a five-day simulation-based learning program. More specifically, this study investigated: (a) how the student placement impacted the workload and role of the CE, (b) the level of student preparedness, and (c) the CEs' thoughts about simulation.

\section{Method}

Ethical approval for the research was obtained from the relevant ethics committees at all six universities involved in the RCT (Hill et al., 2020).

Participants. Participants were 35 CEs who were SLPs employed in traditional workplace settings providing services for adults with communication and swallowing difficulties who provided clinical placements for students who had been randomly allocated to Group 2, the 'simulation+traditional' arm of the RCT (Hill, et al, 2020). The CEs were aware of the overall focus of the simulation-based learning program, however, to limit pre-judgement of students' performance and learning outcomes and to ensure valid assessment of their clinical skills, the CEs were not provided with specific information on learning objectives, activities, or students' progress (see Hill et al., 2020).

Of the 35 CEs, 25 (71\%) had less than five years of experience providing clinical education in the workplace and the remaining $10(29 \%)$ reported more than five years of experience as a CE. Three CEs had more than 15 years of clinical education experience. The total number of students supervised by participating CEs across their careers ranged from one to over 100: 10 CEs had supervised between zero to five students, $18 \mathrm{CEs}$ had supervised between six and 25 students, two had supervised between 26 and 50 students and nine had supervised over 50 students. The majority (51\%) of CEs supervised students in pairs (ratio of 2:1, student to CE) following completion of the five-day simulation-based learning program. Ten (29\%) CEs provided supervision in a 1:1 model, two supervised three students together (ratio 3:1) and five supervised groups of four students (ratio 4:1).

Data collection. Data was collected from CEs using a semi-structured interview guide (see Appendix B). The interview guide was developed by a working group of the project team, including members with extensive experience working in simulation and in traditional adult 
settings. The guide was then reviewed to ensure ease of understanding and to check that interview questions and prompts would provide CEs with the opportunity to discuss their perceptions of student learning and the simulation-based learning program in detail.

The first section of the interview obtained information about the SLPs' level of experience specifically in relation to clinical education. Sections 2, 3 and 4 investigated the participating CEs' perceptions of the student/s, based on their own observations and experiences as a CE. Section 2 explored the impact of the students on the CE's workload and role, the level of learning support required, and any comparisons with previous clinical education roles. The third section asked CEs about students' preparedness and readiness for the traditional workplace placement and skills believed to have been brought from the simulation-based learning program to the placement, while the fourth section explored CEs' general views on simulation.

Procedure. Research team members at each university contacted the CEs who supervised students in their workplace following completion of the five-day simulated learning program and invited their participation in the study. Contact details for consenting CEs were forwarded to a research assistant, independent of the project, who contacted the CEs within two weeks of placement completion to schedule an interview. The finalized interview guide was discussed with the research assistant to ensure consistency in delivery of interview questions. All interviews were conducted over the phone by this research assistant at a time convenient to the CEs and audio recorded. Length of interviews ranged from 13 to 49 minutes (average 27.4 minutes). Variations in interview length were related to the CEs' level of experience, the number of students reflected on by the $\mathrm{CE}$, and/or time constraints within the workplace. All interviews were transcribed verbatim by two research team members (DA and EC).

Data Analysis. Thematic analysis of the 35 interview transcripts was undertaken. Initial qualitative content analysis followed the processes outlined by Graneheim and Lundman (2004). All interviews were read through in entirety several times to obtain a sense of each separate interview. Following this, each interview text was divided into meaning units, these meaning units were condensed and labelled with a code. Codes were then sorted into subcategories. Related subcategories were subsequently grouped into categories and then themes. An example of the analysis from meaning unit to sub-categories is provided in Table 1.

To ensure the credibility of data analysis, the following procedure was undertaken. Two research team members (EC and DA) coded the first five interviews independently then met to discuss their coding and reach consensus. One of these researchers coded a further five interviews and two of these were reviewed by the other. The two researchers then met to establish consensus of the codes. Codes were then reviewed by an additional three members of the research team to ensure consistency in code development ( $\mathrm{SH}, \mathrm{JW}, \mathrm{AH})$. Subcategories and categories were then formulated by these five research team members and the underlying meaning of the categories were formulated into provisional themes pending analysis of the remaining interviews. The remaining 25 interviews were coded by one of the research team members (DA) to ensure a depth of understanding of all CEs' perspectives (Braun \& Clarke, 2019). Twenty percent of all interviews were re-coded by the second researcher (EC) to enhance credibility of the data and analysis. Consensus of the final sub-categories, categories, and themes as presented in the results was then identified through discussion involving the same five research team members. 


\section{Table 1}

Examples of Meaning Unit Analysis, Condensed Meaning Unit, Code, and Sub-Category

Meaning unit

"So, from a clinical educator perspective, that was really helpful for me and I felt like we could just hit the ground running earlier than normal." TR007

"...overall, they were all pretty good at having done those things, transferring that over here..." TR019

“...it didn't take a long time to get her, you know, to understand exactly what we were doing and using those clinical skills ..." TR030

\begin{tabular}{|c|c|c|}
\hline $\begin{array}{l}\text { Condensed meaning } \\
\text { unit }\end{array}$ & Code & Sub-category \\
\hline $\begin{array}{l}\text { Students hit the ground } \\
\text { running }\end{array}$ & $\begin{array}{l}\text { Students able to hit } \\
\text { the ground running }\end{array}$ & $\begin{array}{l}\text { Transferability of skills } \\
\text { and prior learning }\end{array}$ \\
\hline $\begin{array}{l}\text { Students transferred } \\
\text { skills learned in } \\
\text { simulation to the } \\
\text { clinical setting } \\
\text { Student didn't take a } \\
\text { long time to use clinical } \\
\text { skills }\end{array}$ & $\begin{array}{l}\text { Students transferred } \\
\text { skills learned in } \\
\text { simulation } \\
\text { Student only took a } \\
\text { short time to apply } \\
\text { relevant clinical } \\
\text { skills }\end{array}$ & \\
\hline
\end{tabular}

\section{Results}

Four main themes were identified through analysis of the transcripts of CEs' perceptions of students in the workplace following completion of the simulation-based learning program. Each theme is discussed in detail and a summary of each theme generated from the underlying meaning of categories and subcategories is provided in Table 2.

\section{Table 2}

Themes, categories, and subcategories identified from the data

\begin{tabular}{|c|c|c|}
\hline Themes & Category & Subcategories \\
\hline \multirow[t]{4}{*}{$\begin{array}{l}\text { 1. Impact of students } \\
\text { in the workplace }\end{array}$} & Benefits of having students & $\begin{array}{ll}\text { - } & \text { Ability to fulfil role requirements } \\
\text { - } & \text { Students assisted workload and role } \\
\text { - } & \text { Contributions to department } \\
\text { - } & \text { CE development }\end{array}$ \\
\hline & Challenges to having students & $\begin{array}{l}\text { - Demands of working with challenging students } \\
\text { - Challenges relating to workload and role } \\
\circ \quad \text { Reduced clinical efficiency } \\
\circ \quad \text { Increased workload }\end{array}$ \\
\hline & Students are different & $\begin{array}{ll}\text { - } & \text { Strong students } \\
\text { - } & \text { Challenging students }\end{array}$ \\
\hline & $\begin{array}{l}\text { Variable levels of learning support } \\
\text { required }\end{array}$ & $\begin{array}{l}\text { - Students required less learning support or an } \\
\text { appropriate amount of learning support } \\
\text { - Students required increased or significant level } \\
\text { of learning support }\end{array}$ \\
\hline \multirow[t]{2}{*}{$\begin{array}{ll}\text { 2. Simulation primes } \\
\text { learning }\end{array}$} & Approach to learning & $\begin{array}{ll}\text { - } & \text { Attitude toward clinic } \\
\text { - } & \text { Willingness } \\
\text { - } & \text { Engagement in learning }\end{array}$ \\
\hline & Foundational skill development & $\begin{array}{l}\text { - Clinical knowledge and skills } \\
\circ \text { Knowledge and reasoning } \\
\circ \text { Clinical skills } \\
\text { - Professional knowledge and skills } \\
\circ \text { Communication/interpersonal skills } \\
\circ \text { Professionalism }\end{array}$ \\
\hline
\end{tabular}


- Reflection skills

- Working with others

- $\quad$ Preparedness

3. $\begin{aligned} & \text { Student transition } \\ & \text { from simulation to } \\ & \text { traditional } \\ & \text { workplace } \\ & \text { placements }\end{aligned}$
Student readiness
Student learning transition


$\begin{aligned} & \text { Students' and CEs' expectations } \\ & \text { Logistical transition and impact on } \\ & \text { overall placement }\end{aligned}$

- Readiness

- Comfort

- Environmental transition

- Confidence

- Helpful for transition into traditional placement

- Transferability of skills and prior learning

- Changes to learning progression following simulation

- Student expectations

- CE expectations

- $\quad$ CE unaware of simulation program content

- Logistical transitions

- Changes to learning environment and context

4. The role of Benefits of simulation
simulation in
clinical education
programs

Limitations of simulation and uncertainly around the impact of simulation

Future use of simulation
- General

- Students like and value it

- Ideal learning environment

- Good for early skill and knowledge development

- Addresses issues with student placement

- Limitations of simulation/placement

- Unsure of impact of simulation/impact on students

- Students would have benefited from more time in traditional setting

- Suggested changes to simulation-based learning program

Benefits and challenges of having students. Many CEs suggested that the supervision of students on traditional placements following the simulation-based learning program led to changes in workload, increased efficiencies, and contributions to the department. One CE commented, "We saw a lot more patients," and another said, "Definitely in rehab, [the student] really helped the two speechies that normally work in there, because it did free up a lot of their workload so that they could do a lot of, some of those maybe non-clinical tasks that they don't normally get a chance to do." However, other CEs described time management challenges when supervising students:

Being able to manage your time with the amount of people to see that day because, I guess, it does just take a lot longer with the students.... So, I think time management is difficult when you're attempting to judge how long it will take on someone else's behalf.

While the CEs described increased demands on and changes to their roles and workloads (e.g., suspending research, reducing administrative load, adjustments to caseload), they also noted that students enabled opportunities for personal and professional development and made a significant contribution to the department. One CE commented having a student was “... 
beneficial for my learning and skill development around clinical education and communication with students, I guess, and while it was - it was quite challenging, I think it was a really good learning experience for me too."

Students are different and require variable levels of learning support. Typically, CEs described both positive and challenging overall student supervision experiences. CEs reported that most of the students completing traditional placements following simulation were "really good," developed well, were competent, strong, and an asset to the department and, therefore, required less scaffolding or minimal support, particularly in the first few weeks of the placement compared to other students. In particular, one CE indicated:

... they didn't need as much scaffolding from me as previous placement ... they also, I think, had kind of formulated a bit of a team bond and knew how each other worked, and knew each other's strengths, and provided each other with really good support... these students demonstrated that very early on.

However, a few CEs described students that were challenging, who didn't progress, and lacked knowledge, skills, and confidence. These students were more reliant on the $\mathrm{CE}$ and required different types and levels of support to complete tasks and develop skills; one CE noted, "... so, in addition to the learning support required, she needed a lot more reassurance and encouragement throughout the placement."

Theme 2: Simulation primes learning. This theme represented CE perceptions that the simulation-based learning program conducted prior had primed most students for their traditional placement. CEs reported students were already positively engaged in the learning process at the time they started in their traditional placement and demonstrated development of important foundational skills necessary for further learning in a real clinical environment. In some instances, the CEs directly compared students following simulation to students they had previously supported. They attributed these differences to the priming achieved through the simulation-based learning program, as highlighted by one of the CEs:

Yeah, fundamental sort of generic skills that underlay capacity to learn or develop skills in those clinical competencies. So, I found that even when I looked at [assessment tool] they for me were marked higher in the aspect of professionalism at mid-placement than other students. They were just ready to work in a health setting.

Approach to learning. The majority of CEs reported students to be motivated, enthusiastic, open, and interested in learning during the traditional placement. They also demonstrated a willingness to listen, experience, and engage with other professionals. CEs mostly reported an active approach to learning suggesting that the students were willing to "jump in" and "have a go" early on in the placement. For example, one CE stated:

Yeah, they just seemed yep very, very happy, and confident, and very willing to start, and ready to go straight away.... They didn't drag themselves in there, they were ready to go and hit the wards and discuss things...and sometimes in that orientation session students sort of sit there, but they seemed very engaged and were asking a lot of questions and wanting to know more and sharing a lot of things.

In contrast, some CEs commented that students lacked initiative and demonstrated "some issues with wanting to be told what to do rather than using their initiative." One CE reported 
concern about a student "not directing learning or taking ownership of that and not following through with plans or even sometimes feedback." Students reportedly encouraged, and were receptive to, feedback that could improve their clinical practice skills. Furthermore, CEs also described students as learners who were self-directed and independently searched relevant literature and engaged in discussions with peers. One CE explained, “... their reflective practice skills were fantastic, ... as well as their self-directed and learning skills ... that is the key [to] learning and the confidence to be able to provide feedback and see feedback from their peers as well."

Foundational skill development. This category represented agreement among CEs that the majority of students presented with well-developed professional skills and foundational clinical knowledge and skills to support their learning and performance within the workplace. In particular, most students were reported to have strong communication and interpersonal skills which facilitated rapport building and effective interactions with patients, as one CE stated, her student had "... lovely manner and rapport with patients ... just has a very strong patient focus." Another CE commented:

Initially it meant that I didn't have to spend so much of my time covering the basics that we would normally have to cover with students who were completely unfamiliar with the setting. I found with this group of students that targeting things like communicating with the patient or how do you talk to Mr Smith who has just had a stroke... I think that they'd come from a week of communicating with simulated patients, and so I found a lot of those things I didn't have to address as much.

Some CEs made comparisons to previous students they have supervised, suggesting that following simulation, students were more professional, demonstrating good time management, organizational skills, and accountability. One CE reported:

Even logistics in terms of being able to be able to go and greet ... the clients in the waiting room and escorting them into the room and making sure that the room is set up for the client ... they're actually more mindful of those things in comparison to other students. They were also much better at understanding time ... they were more mindful of their daily schedule of times that they had to get through and they had to work quite efficiently to get everything they needed to have done during the day.

Students' knowledge of the multidisciplinary team and their ability to work well with their peers was also noted by almost all CEs. One commented, "They bring with them an awareness of where we fit in the continuum of care, and an awareness of who the team members [are] ... and how the team functions as well."

CEs reported that nearly all students commenced the traditional placements with good theoretical knowledge and skills (or evidence of clinical experience). This was particularly true in specific clinical areas, for example, dysphagia, and the ability to conduct structured bedside clinical assessments. One CE indicated, "They were very prepared in terms of being able to do basic assessments, so like the oromotor assessment they were able to do straight away. They were quite good at reading files and understanding what they were reading." However, some CEs reported students had difficulty with reasoning skills, particularly associated with goal setting and therapy planning, often seeking CE support for these skills. One CE stated, “... their session plan did not include any rationale, so they just came to us consistently asking about how 
they should approach it. We would often go back to them saying you need to go back to the literature."

The CEs also commented specifically on students' reflection skills, suggesting that most students had good reflective practice which aided their learning in the workplace setting. Some CEs directly attributed these skills to the students' simulation experience, for example, “... if I were to credit it to their simulation that it requires less work of me because the student came prepared with self-reflection tools. So, for example, that keep/start/stop strategy, that was something that she just automatically started using." A small number of students, however, were reported to have limited self-reflection skills and insight while on placement.

Theme 3: Student transition from simulation to traditional workplace placements. The third theme synthesized CEs' discussions regarding the transition and links between the simulation-based learning program and traditional workplace placements (see Table 2). There were five categories within this theme including students' readiness, adjustment and transition to learning in a traditional placement, the expectation of the students and CE, as well as logistical transitions.

Student readiness. Overwhelmingly, CEs described students who were primed, engaged, and motivated to complete their traditional placement in the workplace, as articulated in theme one. It was also noted that students were very prepared for this transition having completed prerequisite activities/reading and compiled relevant documents and resources specific to the clinical environment. Many students presented with resources ready to go, pre-written checklists, and clarity about their learning within the clinical context. Some CEs specifically compared the level of preparedness to previous students they had on placement, for example, "In comparison to students who hadn't done sim[ulation], they were probably $50 \%$ more prepared for the placement than previous students." Another CE commented, "Even though they were technically less experienced than the previous students, they were far better prepared."

Adjustment to placement. Students' experiences in the simulation-based learning program supported their transition to the real clinical environment. Students reportedly appeared familiar with the environment, knowing what to expect in the hospital/clinical setting, and seemed more comfortable and better able to adjust. As one CE commented, "They just had that sense of familiarity or comfortable sense."

Student confidence was discussed by all CEs and was seen to impact how well students transitioned into the traditional placement. While the majority of students were reportedly more confident overall and with specific tasks (e.g., interacting with patients, engaging with the multidisciplinary team, using skills learned in simulation), some CEs also noted a few students who remained intimidated by the new workplace environment and placement overall. Additionally, CEs commented on a small number of students who presented as overconfident in the traditional placement.

Student learning transition. The CEs also reported that students were able to transfer learning from simulation to the workplace and commented on positive changes to students' learning progression following simulation in that students demonstrated better learning strategies enabling extension of learning to happen sooner in the placement. Many CEs reported that students demonstrated very rapid application and transfer of knowledge and skills, both clinical and professional, within the clinical setting, which enabled direct patient contact more readily 
than normal. However, a few CEs also described students that had difficulty applying what they had learned in the simulation-based learning program and were less accepting of variations to the processes and procedures previously learned.

The CEs commonly noted that students used a variety of learning strategies in the workplace following the simulation-based learning program and felt that these enabled more rapid achievement of learning outcomes during the traditional placement. One CE commented, "I think the learning outcomes were more in the environment [workplace placement] because of that timing [being post simulation]," and then suggested, "these students were less fearful of the unknown ... further along that continuum to being open to learn than other students."

Students' and CEs' expectations. This category describes the expectations of learning and development in both the simulation-based learning program and traditional workplace placements. The CEs discussed students' expectations about learning opportunities in the traditional placement as well as their own expectations of the students' knowledge, skills, and competency development following simulation.

While most students were aware of what to expect from the environment, some had unrealistic expectations about learning opportunities, caseload, and the progression of their learning. One CE noted:

So, she came in with really high expectations and verbally could, you know, in the first week demonstrate a lot of knowledge, but then once we got down to the nitty-gritty of it and the new setting, she really wasn't meeting my expectations....

CEs often reported that students met or exceeded their expectations, particularly regarding the level of independence when compared to previous students they had supervised. One commented that the students "were able to be more independent... as independent as you can be as a student, like, probably faster than on previous placements" and another CE reported:

They were actually able to do quite a lot more independently in that third week than previous placements that I have had ... very willing and eager to learn and took on a lot of my feedback and I was able to give them a little bit more independence which is kind of good.

However, there were also specific clinical areas where CEs expected the students to be more work-ready (e.g., with an aphasia caseload, writing session plans).

Logistical transition. CEs reflected both positively and negatively on the transition of students from the simulation-based learning program into the traditional placement. Many noted that the initial stages (or first few weeks) of the placement in the workplace was much easier, the students required less orientation and support to understand the environment, and started to see patients earlier. However, others felt the transition was disjointed and there was some duplication of orientation tasks (e.g., code of conduct, hand hygiene practices). All CEs wanted to know more about the content, experiences, and learning outcomes provided in the simulation-based learning program. For example, one CE reported:

I didn't know exactly what they had done in the simulation before they came... but I found that I was asking a lot, you know... What did you do? How did this? .... What we are doing now compared to what you did?... trying to find where they were starting off at.

Theme 4: Role of simulation in clinical education programs. This theme related to the CEs' overall impressions of simulation and role of simulation in clinical education. Three categories 
were identified including the perceived benefits of simulation, the limitations and uncertainty regarding the impact of simulation, and future use of simulation.

Benefits of simulation. In general, CEs reported that students liked and valued simulation as a clinical learning experience. Simulation was described by CEs as an ideal learning environment, good for early skill and knowledge development, and enabled the profession to address issues with student placements. While being seen to enhance outcomes for stronger students, improvements to learning outcomes was also viewed as helpful for struggling students. One CE reflected, "the sim[ulation] got her to the point where I passed her ... My thoughts are that if she hadn't had sim[ulation], then I would have had a really hard time with her."

Limitations of simulation and uncertainty around the impact of simulation. Many CEs perceived differences in how students responded to the simulation and progressed in the traditional workplace placement. In particular, one CE indicated:

So, I think all of that comes back to the personality of the students themselves, and that one of them learned a lot more about the environment and the context on sim[ulation] and the other took on more of an assumed confidence.

The CEs were also unfamiliar with the structure and content of the simulation-based learning program, and, therefore, remained unsure about the impact of students' engagement in simulation on their progress and performance during the traditional placement. One CE said, "It's a bit tricky because I don't know exactly what they were exposed to in the simulation clinic." Some CEs highlighted the differences between simulation and "real" clinical environments, indicating that while simulation was a good adjunct to traditional placement, it could not replace real clinical experience. One CE commented, "I think it's a really good facelearning tool. However, I struggle to see how it can replace the steep learning curve required once they come into a placement to learn all .... the unspoken rules of how things operate."

Future use of simulation. CEs were somewhat interested to see simulation integrated as a mode of learning to support students' development of professional skills and competencies. Suggestions for specific knowledge and skills to focus on in future simulation-based learning programs included: inter-professional communication, written documentation, searching literature, and finding evidence to support clinical practice and reasoning. It was also suggested that simulation could be used to extend clinical skills and knowledge areas for students who are progressing well.

\section{Discussion}

This study explored the perceptions of CEs who supported SLP students on a traditional workplace placement following a five-day simulation-based learning program. Findings from this study revealed that, overall, CEs identified simulation as a means by which students could prepare for and transition into their traditional placement, thereby maximizing their learning and experience time. While literature has explored the perspectives of SLP students following their participation in simulation as a learning experience, this is one of the first studies investigating the perceptions of CEs about their students' learning in traditional placements following a structured simulation-based learning program. Findings from this study provide insight and recommendations into the development of future simulation-based learning programs and strategies which better support students and CEs to maximize learning in the transition from simulation to a traditional placement. 
There are several key outcomes of this research. First, CEs generally reported that the simulation-based learning program primed and prepared students for learning in the workplace. This project situated a simulation-based learning program immediately prior to a traditional workplace placement, so learning outcomes were focused on providing students with knowledge and skills to support the transition into their first traditional placement in an adult setting. The contribution of simulation to preparation of students for placement has been previously reported (Larue et al., 2015). Therefore, it is not surprising that the focus of the CE reflections was around student preparedness and readiness for learning. This readiness was discussed as an important facilitator of the students' overall learning.

Willingness to learn, professionalism, and effective communication skills have been reported as critical to placement experiences and success (Chipchase et al., 2012). The findings of the current research specifically highlighted that the simulation-based learning program facilitated the development of generic professional skills, including communication, professionalism, and reflection that enabled the students to engage in learning opportunities at a faster rate earlier in the traditional workplace placement.

It is well documented that simulation provides students with a safe and consistent learning environment (Weller et al., 2012) which allows for repeated practice of skills (Ker \& Bradley, 2014). Repetition builds self-efficacy and self-belief in a person's own ability to complete designated tasks (Bandura, 1977). Confidence and self-efficacy facilitate one's willingness to readily engage in tasks, to "jump in" and learn, build skills, and then repeat tasks for enhanced learning. CEs in the current study specifically reflected on students' increased confidence at the beginning of the traditional placement to engage in basic clinical tasks and the new environment. This finding extends previous research that indicates that SLP students are more confident following completion of simulated learning experiences (Hill et al., 2012; Miles et al., 2016; Penman et al., 2020), and suggests that students' increased confidence can transfer to their performance in a real clinical setting.

Outcomes of this study have provided further understanding of the possible transferability of knowledge and skills from simulation to traditional workplace placement. Worldwide, the majority of SLP students' clinical experiences are facilitated in traditional placements, so it is important to determine if a simulation-based learning program is useful and beneficial in supporting and enhancing learning in traditional placements. The five-day simulation-based learning program undertaken by the students in this study included 13 different simulations that involved a range of different learning objectives, cases, scenarios, and modes of simulation across the continuum of care in adult clinical practice (Hewat et al., 2020). While the program provided students with knowledge and skills across a range of practice areas and competencies, some CEs perceived that students' clinical skills were very task specific and that students had less confidence and ability to transfer skills to the needs of the "real" clinic. That is, if the tasks and procedures were not included in the simulation-based learning program, some students didn't necessarily have the immediate ability to transfer and apply these skills at their current level of learning. Previous literature has reported that simulation is good for specific skills development (e.g., clinical swallow exam; Potter \& Allen, 2013), advanced skill/competency development (Ward et al., 2015), providing guaranteed learning opportunities in specific scenarios (Howells et al., 2019; Miles et al., 2016; Penman et al., 2020), and providing learners with opportunities for repeated practice (Ker \& Bradley, 2014). Therefore, in light of current findings, educators should consider carefully the structure and focus of future simulated learning programs and how these articulate with learning opportunities and expectations in traditional placements. 
Results of the present study also suggested that many students readily applied skills learned in simulation, while other students had difficulty applying what was learned or performing new tasks not performed within simulation. Reflections of the CEs also reinforced the need to enhance communication between education providers and workplaces to ensure CEs supervising students in traditional placements are aware of the structure and content of simulated learning programs and have realistic expectations of students' performance. This awareness enables scaffolding of the transition from simulation to traditional placements by supporting students to see similarities and differences between the two environments and openly discuss transferrable skills. The majority of CEs in this study reported that students were able to get the most out of their learning after simulation, stronger students were able to advance more, and students experiencing challenges could draw on their learning from simulation. Despite the notable benefits of simulation in priming students for learning in workplace placements, the results suggest that for a small number of students, simulation doesn't necessarily assist in redressing innate student-specific learning issues. The complexity and individuality of students and student learning in clinical contexts remains constant. Further research could explore specific changes to teaching and learning support that educators employed with students to maximize their outcomes.

\section{Limitations and future directions}

While the results of this research are drawn from a large number of CEs, participation was limited by the constraints of the primary study (Hill et al., 2020). That is, recruitment occurred only through the six participating universities providing SLP education in the Australian context. Further, the CEs' perspectives were drawn specifically from their observations of the students in their workplace without detailed knowledge of the simulation program. As noted earlier, this was to ensure CE assessment of students' knowledge, skills, and competency in the workplace was not influenced or biased by prior information. To further understand the role of simulation in developing skills and preparing students for workplace placements, future research could compare not only the CEs' perceptions of students in the workplace with and without simulation, but also students' levels of confidence and anxiety with and without simulation prior to commencing a traditional workplace placement.

Future research could also address some of the limitations of the current study by gathering additional perspectives about the effectiveness of simulated-learning programs from all stakeholders, including simulation facilitators, simulated patients, students, and university faculty. Further, given the acceptance of simulation as a positive learning tool for developing clinical skills within an adult setting, its use to support learning in other caseload areas such as pediatrics, complex clients, interprofessional, and school settings should be explored.

\section{Conclusion}

Clinical education is essential to training SLPs. In this study, the perceptions of workplace CEs suggest that the use of a simulation-based learning program immediately prior to a traditional placement in the workplace primes and prepares students for placements and may be a useful contribution to the students' overall clinical program. However, simulation-based learning should be viewed realistically in terms of student benefits and programs developed in line with curriculum to enhance student learning experiences as they transition through their clinical education program. 


\section{Disclosures}

This research forms part of the Embedding Simulation in Clinical Training in Speech Pathology project, supported by funding from the Australian Government, Department of Health, under the Simulated Learning Environments Program.

\section{References}

Bandura, A. (1977). Self-efficacy theory: Toward a unifying theory of behavioural change. Psychological Review, 84, 191-213. https://doi.org/10.1037/0033-295X.84.2.191

Blackstock, F. C., Watson, K. M., Morris, N. R., Jones, A., Wright, A., McMeeken, J. M., ... Jull, G. A. (2013). Simulation can contribute a part of cardiorespiratory physiotherapy clinical education. Simulation in Healthcare, 8(1), 32-42. https://doi.org/10.1097/SIH.0b013e318273101a

Braun, V., \& Clarke, V. (2019). Reflecting on reflexive thematic analysis. Qualitative Research in Sport, Exercise and Health, 11(4), 589-597. https://doi.org/10.1080/2159676X.2019.1628806

Briffa, C., \& Porter, J. (2013). A systematic review of the collaborative clinical education model to inform speech-language pathology practice. International Journal of SpeechLanguage Pathology, 15(6), 564-574. https://www.doi.org/10.3109/17549507.2013.763290

Cantatore, F., Crane, L. H., \& Wilmoth, D. (2016). Defining clinical education: Parallels in practice. Australian Journal of Clinical Education, 1, 1-8. https://ajce.scholasticahq.com/article/5087

Chipchase, L. S., Buttrum, P.J, Dunwoodie, R., Hill, A. E., Mandrusiak, A., \& Moran, M. (2012). Characteristics of student preparedness for clinical learning: clinical educator perspectives using the Delphi approach. BMC Medical Education, 12, 112. https://doi.org/10.1186/1472-6920-12-112

Council for Clinical Certification in Audiology and Speech-Language Pathology of the American Speech-Language-Hearing Association. (2013). 2014 Standards and Implementation Procedures for the Certificate of Clinical Competence in SpeechLanguage Pathology. http://www.asha.org/ Certification/2014-Speech-LanguagePathology-Certification-Standards/.

Delany, C., \& Molloy, E. (2018). Learning and teaching in clinical contexts: A practical guide. Elsevier.

Dudding, C. C., \& Nottingham, E. E. (2018). A national survey of simulation use in university programs in Communication Sciences and Disorders. American Journal of SpeechLanguage Pathology, 27(1), 71-81. https://www.doi.org/10.1044/2017 AJSLP-17$\underline{0015}$

Graneheim, U. H., \& Lundman B. (2004). Qualitative content analysis in nursing research: concepts, procedures and measures to achieve trustworthiness. Nurse Education Today, 24(2), 105-12. https://www.doi.org/10.1016/j.nedt.2003.10.001

Hayden, J.K, Smiley, R.A., Alexander, M., Kardong-Edgrens, S., \& Jeffries, P.R. (2014). The NCSBN national simulation study: A longitudinal, randomized, controlled study replacing clinical hours with simulation in prelicensure nursing education. Journal of Nursing Regulation, 5(2), S3-S40. https://doi.org/10.1016/S2155-8256(15)30062-4

Hewat, S., Penman, A., Davidson, D., Baldac, S., Howells, S., Walters, J., Purcell, A., Cardell, E., McCabe, P., Caird, E., Ward, E., \& Hill, A.E. (2020). A framework to support development of quality simulation-based learning programs in speech-language 
pathology. International Journal of Language \& Communication Disorders, 55(2), 287-300. https://doi.org/10:1111/1460-6984.12515

Higgs, J. (2012). Practice-based education. In J. Higgs, R. Barnett, S. Billett, M. Hutchings, \& F. Trede (Eds.), Practice-based education: Perspectives and strategies, pp. 3-12. Sense Publishers.

Hill, A.E., Davidson, B. J., \&. Theodoros, D. G. (2012). Speech-language pathology students' perceptions of a standardised patient clinic. Journal of Allied Health, 42(2), 84-91. https://doi.org/10.1111/j.1460-6984.2012.00154.x

Hill, A.E., Ward, E., Heard, R., McAllister, S., McCabe, P., Penman, A., ... Walters, J. (2020). Simulation can replace part of speech-language pathology placement time: A randomised controlled trial. International Journal of Speech-Language Pathology.

Howells, S., Cardell, E.A, Waite, M.C., Bialocerkowski, A., \& Tuttle, N. (2019). A simulationbased learning experience in augmentative and alternative communication using telepractice: Speech pathology students' confidence and perceptions. BMC Advances in Simulation, 4(23). https://doi.org/10.1186/s41077-019-0113-x

Imms, C., Froude, E., Chu, E. M., Sheppard, L., Darzins, S., Guinea, S., ... Mathieu, E. (2018). Simulated versus traditional occupational therapy placements: A randomised controlled trial. Australian Occupational Therapy Journal, 65(6), 556-564. https://doi.org/10.1111/1440-1630.12513

Johnson, R., Bourne, E., Sheepway, L., \& McAllister, L. (2017). Expanding volume and quality of clinical placements. Journal of Clinical Practice in Speech Language Pathology, 19(2), 93-99.

Ker, J., \& Bradley, P. (2014). Simulation in medical education. In T. Swanwick (Ed.), Understanding medical education: Evidence, theory and practice $\left(2^{\text {nd }}\right.$ ed., pp. 175192). Wiley Blackwell.

Larue, C., Pepin, J., \& Allard, E. (2015). Simulation in preparation or substitution for clinical placement: A systematic review of the literature. Journal of Nursing Education and Practice, 5(9), 132-140. https://doi.org/10.5430/jnep.v5n9p132

McAllister, L. (2005). Issues and innovations in clinical education. Advances in Speech Language Pathology, 7(3), 138-148. https://doi.org/10.1080/14417040500181239

McAllister, L., \& Lincoln, M. (2004). Clinical education in speech-language pathology. Wiley-Blackwell.

McAllister, S., Lincoln, M., Ferguson, A., \& McAllister, L. (2011). A systematic program of research regarding the assessment of speech-language pathology competencies. International Journal of Speech-Language Pathology, 13(6), 469-479. https://doi.org/10.3109/17549507.2011.580782

McAllister, S., Lincoln, M., Ferguson, A., \& McAllister, L. (2013). COMPASS®: Competency Assessment in Speech Pathology ( $2^{\text {nd }}$ ed.). Speech Pathology Australia.

Miles, A., Friary, P., Jackson, B., Sekula, J., \& Braakhuis, A. (2016). Simulation-based dysphagia training: Teaching interprofessional clinical reasoning in a hospital environment. Dysphagia, 31(3), 407-415. https://doi.org/10.1007/s00455-016-9691-0

Penman, A., Hill, A. E., Hewat, S., \& Scarinci, N. (2020a). Students' perceptions of simulationbased learning in speech pathology: A pilot study. International Journal of PracticeBased Learning in Health and Social Care, 8(1), 1-14. https://doi.org/10.18552/ijpblhsc.v8i1.558

Penman, A., Hill, A. E., Hewat, S., \& Scarinci, N. (2020b). "I felt more prepared and ready for clinic": Connections in student and clinical educator views about simulation-based learning. Australian Journal of Clinical Education, 7, 1-21. 
Potter, N. L., \& Allen, M. (2013). Clinical swallow exam for dysphagia: A speech pathology and nursing simulation experience. Clinical Simulation in Nursing, 9(10), e461-e464. http://dx.doi.org/10.1016/j.ecns.2012.08.001.

Richard, L. F. (2008). Exploring connections between theory and practice: Stories from fieldwork supervisors. Occupational Therapy in Mental Health 24(2), 154-175. https://doi.org/10.1080/01642120802055259

Sokkar, C., McAllister, L., Raymond, J., \& Penman, M. (2019). Supervisors' perceptions of student placements in speech-language pathology private practice: Benefits, challenges and strategies. Speech, Language and Hearing, 22(2), 122-133. https://doi.org/10.1080/2050571X.2019.1607482

Speech Pathology Association of Australia. (2011). Competency-based Occupational Standards (CBOS) for Speech Pathologists: Entry-Level (revised). Speech Pathology Association of Australia. https://www.speechpathologyaustralia.org.au/SPAweb/Resources_For_Speech_Pathol ogists/CBOS/SPAweb/Resources_for_Speech_Pathologists/CBOS/CBOS.aspx?hkey $=\mathrm{c} 1509605-\mathrm{c} 754-4 \mathrm{aa} 8-\mathrm{bc} 10-\mathrm{b} 099 \mathrm{c} 1211 \mathrm{~d} 4 \mathrm{~d}$

Speech Pathology Australia (2018). Clinical Education in Australia: Building a Profession for the Future. https://www.speechpathologyaustralia.org.au/SPAweb/Resources_For_Speech_Pathol ogists/Clinical_Education/SPAweb/Resources_for_Speech_Pathologists/Clinical_Edu cation/Clinical_Education.aspx?hkey=fbbaa348-9422-4bc4-87f1-7ebac62aba97

Speech Pathology Australia (2018). Simulation-based Learning Program. https://www.speechpathologyaustralia.org.au/SPAweb/Resources_For_Speech_Pathol ogists/Clinical_Education/Simulation-

based_Learning_Program/SPAweb/Resources_for_Speech_Pathologists/Simulationbased_Learning_Program/Simulationbased_Learning_Program.aspx?hkey=c76641bc-4318-431a-9f5e-a870af826a5a

Ward, E.C., Hill, A.E., Nund, R.L., Rumbach, A.F., Walker-Smith, K., Wright, S.E., Kelly, K., \& Dodrill, P. (2015). Developing clinical skills for paediatric dysphagia management using Human Patient Simulation (HPS). International Journal of Speech-Language Pathology, 17(3), 230-240. http://doi.org/10.3109/17549507.2015.1025846

Watson, K., Wright, A., Morris, N., McMeeken, J., Rivett, D., Blackstock, F., Jones, A., Haines, T., O’Connor, V., Watson, G., Peterson, R., \& Jull, G. (2012). Can simulation replace part of clinical time? Two parallel randomised controlled trials. Medical Education, 46(7), 657-667. https://doi.org/10.1111/j.1365-2923.2012.04295.x

Weller, J.M., Nestel, D., Marshall, S.D., Brooks, P.M., \& Conn, J.J. (2012). Simulation in clinical teaching and learning. Medical Journal of Australia, 196(9), 594. https://doi.org/10.5694/mja10.11474

Zraick, R.I. (2013). Review of the use of standardized patients in speech-language pathology clinical education. International Journal of Therapy and Rehabilitation, 19(2), 112118. https://doi.org/10.12968/ijtr.2012.19.2.112 


\section{Appendix A}

Summary of the five-day simulation-based learning program in adult speech-language pathology completed immediately prior to traditional clinical placement (see Hewat et al., 2020 and Hill et al., 2020 for further details regarding simulation activities).

\begin{tabular}{|c|c|c|c|c|c|}
\hline & DAY 1 & DAY 2 & DAY 3 & DAY 4 & DAY 5 \\
\hline \multirow[t]{2}{*}{$\mathrm{AM}$} & \multirow[t]{2}{*}{$\begin{array}{l}\text { Commence simulation- } \\
\text { based learning program } \\
\text { and clinical placement } \\
\text { - General introduction to } \\
\text { Simulation } \\
\text { - Orientation to simulation } \\
\text { clinical environment \& } \\
\text { policies and procedures }\end{array}$} & \multirow[t]{2}{*}{$\begin{array}{l}\text { Simulation } 3 \\
\text { "Tom" } 65 \text { year old male } \\
\text { post left hemisphere } \\
\text { stroke (inpatient } \\
\text { rehabilitation) } \\
\text { - Continuation of therapy } \\
\text { session }\end{array}$} & \multirow[t]{2}{*}{$\begin{array}{l}\text { Simulation } \\
\text { "Margie" 66 year old female } \\
\text { post left hemisphere stroke } \\
\text { (inpatient acute) } \\
\text { - Conduct initial bedside } \\
\text { screening assessment } \\
\text { (oromotor examination and } \\
\text { clinical swallow } \\
\text { examination }(\mathrm{CSE}))\end{array}$} & \multirow{2}{*}{ 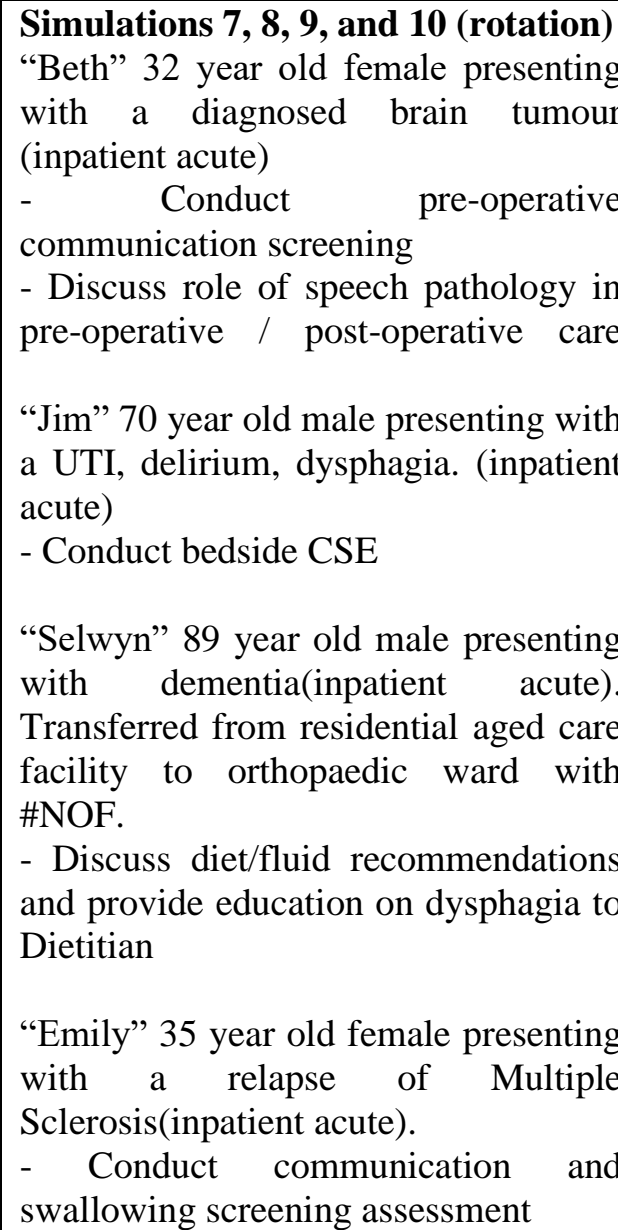 } & $\begin{array}{l}\text { Simulation } 12 \\
\text { "Jim" } 70 \text { year old male } \\
\text { presenting with a UTI, delirium, } \\
\text { dysphagia preparing for } \\
\text { discharge from acute hospital. } \\
\text { - Discuss result of VFSS with } \\
\text { Jim and wife, Betty. } \\
\text { - Provide education, } \\
\text { recommendations and strategies } \\
\text { for managing modified diet and } \\
\text { fluids at home. }\end{array}$ \\
\hline & & & & & $\begin{array}{l}\text { Simulation } 13 \\
\text { Case conference } \\
\text { - Present verbal summary of one } \\
\text { patient (presentation, diagnosis, } \\
\text { interventions, impressions, } \\
\text { recommendations and follow up } \\
\text { plan) } \\
\text { - Discuss case in conference with } \\
\text { peers and simulation CE }\end{array}$ \\
\hline
\end{tabular}




\begin{tabular}{|c|c|c|c|c|c|}
\hline & & & & $\begin{array}{l}\text { - Discuss role of speech pathology in } \\
\text { long-term care }\end{array}$ & \\
\hline \multicolumn{6}{|c|}{ Lunch } \\
\hline \multirow[t]{2}{*}{$\mathrm{PM}$} & $\begin{array}{l}\text { Simulation } 1 \\
\text { "Tom" } 65 \text { year old male } \\
\text { post left hemisphere } \\
\text { stroke (inpatient } \\
\text { rehabilitation) } \\
\text { - Observe CE-led initial } \\
\text { therapy session }\end{array}$ & \multirow{2}{*}{$\begin{array}{l}\text { Simulation } 4 \\
\text { "Michael" } 36 \text { year old } \\
\text { male (outpatient) 10yrs } \\
\text { post-traumatic brain injury } \\
\text { from motor vehicle } \\
\text { accident } \\
\text { - Conduct dysarthria } \\
\text { assessment } \\
\text { - Analyse results and write } \\
\text { assessment report }\end{array}$} & \multirow{2}{*}{$\begin{array}{l}\text { Simulation } 6 \\
\text { "Margie" } 66 \text { year old female } \\
\text { post left hemisphere stroke } \\
\text { (inpatient acute) } \\
- \text { Conduct speech and } \\
\text { language screening } \\
\text { assessment } \\
\text { - Discuss recommendations } \\
\text { with nursing staff } \\
\text { - Document outcomes of } \\
\text { assessment in file notes }\end{array}$} & \multirow[t]{2}{*}{$\begin{array}{l}\text { Simulation } 11 \\
\text { "Margie" } 66 \text { year old female post left } \\
\text { hemisphere stroke (inpatient acute) } \\
\text { - Conduct bedside CSE review } \\
\text { - Conduct therapy session for receptive } \\
\text { and expressive language difficulties } \\
\text { and dysarthria. }\end{array}$} & \multirow{2}{*}{$\begin{array}{l}\text { End of Simulation based- } \\
\text { learning program } \\
\text { - Document statistics } \\
\text { - Final simulation debrief } \\
\text { - Group discussion re: } \\
\text { knowledge, skill and } \\
\text { competency development and } \\
\text { transferable skills to traditional } \\
\text { clinic placement }\end{array}$} \\
\hline & $\begin{array}{l}\text { Simulation } 2 \\
\text { "Tom" 65-year-old male } \\
\text { post left hemisphere } \\
\text { stroke (inpatient } \\
\text { rehabilitation) } \\
\text { - Conduct initial therapy } \\
\text { session }\end{array}$ & & & & \\
\hline
\end{tabular}




\section{Appendix B}

\section{Semi-structured Interview Schedule}

1. Could you tell me about your level of experience as a clinical educator?

How many years have you taken students?

How many students do you think you may have taken over that time?

2. How do you think having this student impacted on your workload and your role?

Did it influence your clinical efficiency and effectiveness?

How did the students' simulation experience impact on the work required of you at different times in the placement?

Did this student require more or less learning support (than other students)?

What were the benefits to you in your workplace?

What were the challenges for you as a CE?

Was this student placement different than other student placements?

3. Can you comment on the student's preparedness for the placement?

How did the student/s present at the beginning of the placement with you?

Please describe the students' readiness for their workplace clinic.

What did the student bring to your workplace clinic?

What skills do you perceive the students brought from simulation to their placement with you?

4. Having now had this student, what are your thoughts on simulation?

What leads you to say that?

5. Is there anything else you would like to add? 